\title{
Conveying Uncertainty in Prognosis to Patients with ESRD
}

\author{
Sanah Parvez ${ }^{a}$ Khaled Abdel-Kader ${ }^{b}$ Mi-Kyung Song ${ }^{c}$ Mark Unruh ${ }^{a}$ \\ aDivision of Nephrology, Department of Internal Medicine, University of New Mexico, Albuquerque, N.Mex., \\ ${ }^{b}$ Division of Nephrology and Hypertension, Vanderbilt University Medical Center, Nashville, Tenn., and ${ }^{\mathrm{C}}$ Adult and \\ Geriatric Health Division, School of Nursing, University of North Carolina at Chapel Hill, Chapel Hill, N.C., USA
}

\begin{abstract}
Key Words
Uncertainty · Prognosis · Communication .

Physician-patient relations $\cdot$ Truth disclosure
\end{abstract}

\begin{abstract}
Background: Prognosis is a component of medical practice imbued with uncertainty. In nephrology, where mortality rates of elderly patients on dialysis are comparable to those of cancer patients, the implications of prognosis are unavoidable. Yet while most patients with end-stage renal disease (ESRD) desire to hear their prognosis, many nephrologists balk at this prospect in part owing to the uncertainty inherent in prognostic estimates. Summary: In this review, the concept of 'uncertainty' in clinical practice is considered from physician and patient perspectives. From the training perspective, providers learn that uncertainty is inescapable in medicine and develop strategies to manage its presence, including the avoidance of communicating uncertainty to their patients. This presages infrequent discussions of prognosis, which in turn influence patient preferences for treatments that have little therapeutic benefits. A general approach to conveying prognostic uncertainty to ESRD patients includes confronting our own emotional reaction to uncertainty, learning how to effectively communicate uncertainty to our patients, and using an effective interdisciplinary team approach to demonstrate an ongoing commitment to our patients despite the presence of prognostic
\end{abstract}

uncertainty. Key Messages: Uncertainty in prognosis is inevitable. Once providers learn to incorporate it into their discussions of prognosis and collaborate with their ESRD patients, such discussions can foster trust and reduce anxiety for both sides.

(c) 2015 S. Karger AG, Basel

\section{Introduction}

In the practice of medicine, prognosis occupies a liminal space. On the one hand, it is one of the cornerstones of the clinical encounter and medical practice. But on the other, its very nature of requiring to know beforehand (pro: before, gignōskein: know) [1] means abandoning the concrete assurance thought to be more common in diagnosis and treatment and instead turning to engage with the unknown. Prognosis, maybe more than any other component of medical practice, is fraught with uncertainty.

When the diagnosis of an advanced disease is discussed with a patient, their main questions are about prognosis: 'How long?' and 'How well?' [2]. Addressing these questions can be extremely challenging even with well-tested tools. For instance, various prognostic indices exist for predicting the length of survival, but they are not generalizable to heterogeneous populations nor can they provide a clear answer for an individual patient [3]. As for

\section{KARGER 125}

(c) 2015 S. Karger AG, Base

0253-5068/15/0393-0058\$39.50/0

E-Mail karger@karger.com

www.karger.com/bpu
Mark Unruh, MD

901 University Boulevard SE

Science and Technology Park

Albuquerque, NM 87106 (USA)

E-Mail mlunruh@salud.unm.edu 
'How well?' while scales exist to quantify quality of life for patients, the subjectivity in the concept of wellness makes this question a perplexing one for the provider to answer [4].

Uncertainty can be a challenging issue to grapple with in medicine because doctors' identities are contingent on their expertise [5-7]. Indeed, a survey conducted by Christakis of 697 internists found that $60 \%$ felt it was 'stressful' to predict a patient's prognosis [8]. This stress occurs because prognostication is difficult, mired in uncertainty, and of consequence [8].

In nephrology, the importance of discussing prognosis becomes critical when a patient with chronic kidney disease (CKD) starts dialysis and her/his mortality rate approaches that of many types of cancer [9]. Understandably, many doctors are hesitant to discuss prognosis when the outcome is oftentimes bleak [10]. But patients, especially older patients, desire to hear their prognosis, even if it is uncertain $[11,12]$. In addition, the communication of this uncertainty can lead to an improved relationship between physician and patient as they navigate the course of the patient's illness [13-15]. However, communicating prognosis and uncertainty has received little attention in nephrology. This review will address the sources of uncertainty in prognosis, how patients and doctors experience uncertainty, and an approach to communicating this uncertainty to patients with kidney disease.

\section{Sources of Prognostic Uncertainty}

Medicine as we know it emerged as a response to uncertainty. The birth of modern medicine in the late 18th century was, in part, owing to a movement that reconfigured the uncertainty of a patient's illness into a sum of isolated instances of measurable certainty [16]. By breaking apart a patient's illness experience into measurable events that can be quantified through laboratory tests or prognostic scores, we see the continuation of this philosophy today in evidence-based medicine [17]. If the connection between a patient's actual condition and the selection of a diagnostic test is a linked chain, each link is weakened by differing manifestations of uncertainty [18]. Because the prognosis is modified as an illness progresses, the chain of uncertainty appears like a closed loop (fig. 1).

The language of prognosis often involves discussing the possible risks of potential outcomes. Indeed, risk estimates are plentiful, but impossible to apply to an individual person's disease outcome. A single person either will or will not experience an outcome [19]. The individ-

Uncertainty in Prognosis to Patients with ESRD

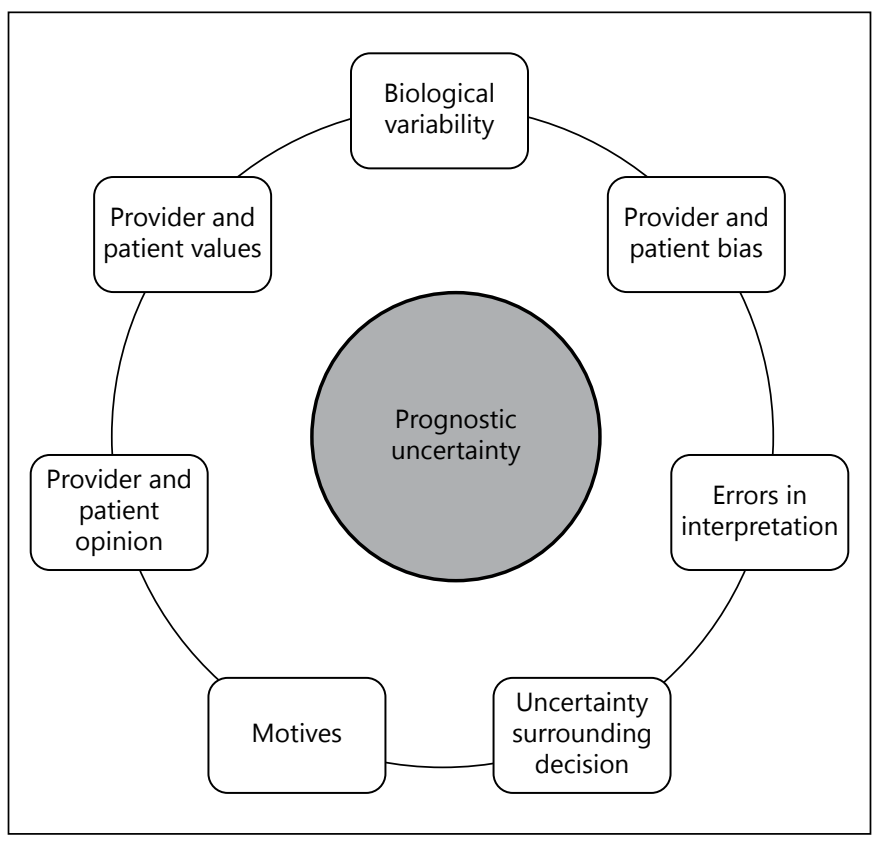

Fig. 1. The loop of patient prognosis. Uncertainty is present in each component. Modified from Eddy [18] and Ghosh [49].

ual application of population-based risk estimates is inherently problematic. Hence, it can be daunting for providers and patients when discussing individual survival times, owing to the nature of the subject and the inherent uncertainty surrounding the available data.

\section{Physician Experience with Uncertainty}

From the outset of their training, physicians quickly encounter the presence of uncertainty, whether it is from their own cognitive limitations or from the gaps and ambiguities that lace through medical knowledge $[17,20]$. Once medical students understand that uncertainty is inherent to medical knowledge, they learn to comfortably manage the limitations of medicine as they accumulate clinical experience [20].

Through their training, providers may learn to cope with uncertainty by ignoring it when communicating with patients and thereby limit patient-provider communication [6]. Indeed, medical students' expressions of uncertainty may increase patient anxiety [21]. One explanation for this strategy is that while trainees and providers confront the presence of uncertainty in medical knowledge, they do not engage with its wide-ranging implications [6]. Despite the facility of disregarding uncertainty, 
such approaches may reinforce paternalism, lead to unrealistic patient/family expectations, and adversely affect patient care and satisfaction [6]. These concerns are salient in patients with serious illnesses and limited prognoses.

In patients with severe acute and chronic illness, treating physicians rarely convey prognostic information. For example, the SUPPORT (The Study to Understand Prognoses and Preferences for Outcomes and Risks of Treatments) trial was a randomized controlled trial to examine whether providing physicians with computer generated prognostic estimates improves end-of-life care [22]. Despite receiving this report, less than $20 \%$ of physicians discussed prognostic information with their patients [22] while most refrained owing to issues of uncertainty [23]. Similarly, when hospice patients requested survival estimates, physicians provided them with frank estimates only $37 \%$ of the time [24].

In nephrology, a similar picture exists of provider reluctance to disclose prognoses for patients with advanced kidney disease. A recent study found that even if patients asked for a prognostic estimate, nephrologists were not able to provide a prognostic estimate for $60 \%$ of them [25] - a greater percentage than observed in providers caring for cancer patients [24]. In another study, 90.4\% of patients with advanced CKD reported that their nephrologist had not discussed prognosis with them [11]. Also, recent studies report that providers clearly discuss non-dialysis prognosis but rarely discuss dialysis prognosis with patients facing the decision about starting dialysis $[26,27]$. While this stance contradicts the recommendations outlined in the Renal Physicians Association/ American Society of Nephrology (RPA/ASN) guidelines for shared decision making with dialysis patients, the comorbid diversity of their patients and uncertainty inherent in prognostication contributes to deterring nephrologists from discussing a critical component of care with their patients $[28,29]$, despite the availability of validated tools for this purpose.

While individual providers manage the challenges of uncertainty differently, prognostic uncertainty remains a major reason for avoiding prognostic discussions [29]. However, avoidance of prognostic discussions, even at the patient's behest, anecdotally appears to outpace the avoidance of communicating treatment risks and benefits, where uncertainty is also inherent. The reasons for this discrepancy are not well characterized, but may include concerns regarding extinguishing hope [11,29], differences in medico-legal implications, or perhaps a feeling that preparing for death lies outside of the nephrology provider's purview. Interestingly, physicians who have been diagnosed with chronic diseases are more open to discussing prognosis and related concerns with their patients [30]. Unfortunately, the failure to disclose prognoses and discuss uncertainty undermines patient autonomy, frequently at a particularly critical moment in the patient's life.

\section{Patient Experience with Uncertainty}

Patients are able to better cope with their treatment decisions when they view their physicians as epistemic authorities [31]. Indeed, expressions of provider uncertainty can cause patients some anxiety. However, the way in which uncertainty is communicated is more important for patient satisfaction than the existence of the uncertainty itself [15, 32-35].

One of the first explorations of this concept was by Johnson and colleagues, who assessed patient views of provider uncertainty by showing them videotapes of hypothetical clinical encounters in which providers expressed uncertainty about prescribing antibiotics and then asked them to rate their satisfaction [33]. Patients were most satisfied when providers expressed no uncertainty, but were the least satisfied when providers expressed uncertainty about antibiotics but then ignored it and prescribed them anyway [33]. The approach used in this experiment limits its generalizability, but these findings support the position that the context of provider uncertainty may influence patient satisfaction.

Gordon and colleagues also assessed the relationship between patient satisfaction and uncertainty by analyzing audio recordings of physician-patient encounters [32]. In their sample, patient satisfaction was positively correlated with uncertainty even though $71 \%$ of physicians expressed uncertainty because providers appeared to compensate for their uncertainty by being more open to building partnerships with their patients [32]. Similar findings were reported in another study [35]. A crosssectional survey of patients about their views of various behavioral and verbal expressions of physician uncertainty found that verbal expressions of physician uncertainty lowered patient confidence in their general practitioner (GP) but behavioral expressions (such as consulting with another GP) increased this confidence [36]. This is especially true of older patients who have known their providers longer [32, 36].

These studies suggest that uncertainty has the potential to improve communication in the clinical encounter
60

Blood Purif 2015;39:58-64 DOI: $10.1159 / 000368954$
Parvez/Abdel-Kader/Song/Unruh 
by encouraging open discussion and facilitating shared decision making, which can increase patient empowerment and satisfaction [35]. This is because discussing uncertainty allows patients to participate in the decisionmaking process to the extent that they desire [34]. Nonetheless, the patient or caregiver perspective on uncertainty specific to prognosis remains largely unknown. A study of 155 surrogates of ICU patients found that a startling $87 \%$ wanted providers to disclose prognostic uncertainty for five main reasons: their 'beliefs that prognostic uncertainty is unavoidable, that physicians are the best and only source for prognostic information, and that discussing prognostic uncertainty leaves room for realistic hope, increases surrogates' trust in the physician, allows surrogates time to prepare to make difficult life support decisions, and to prepare for possible bereavement' [13]. Because of high 1-year mortality rates (20-25\%) for patients on dialysis [9], discussions of prognosis are similarly critical to allow time for patients and their families to make informed decisions and prepare for the future. In addition, uncertainty may create room for hope, which is important to patients when discussing prognosis with their providers $[2,13,15,28,29,37-40]$. Uncertainty can allow a patient and provider to hope for the best, while planning for the worst' $[15,29]$.

\section{Addressing Uncertainty in Clinical Practice}

The implications of prognostic uncertainty are often more meaningful than discussing uncertainty in diagnosis or treatment options, as prognosis gets to the very core of confronting one's own mortality. Therefore, providers must be mindful of the ways in which we approach the communication of this uncertainty with our patients, who are grappling with a difficult illness. For instance, discussion is especially important for patients with advanced CKD, whose choice to initiate or continue dialysis may be influenced by their own view of potential benefits and harms. Below, we outline an approach to addressing uncertainty in nephrology practice by (1) recognizing our own emotional reaction to uncertainty, (2) developing communication skills to increase patient satisfaction, and (3) adopting an effective interdisciplinary team approach to care for patients with ESRD.

In conveying uncertainty to our patients, the first step is to confront our own discomfort with uncertainty and our unwillingness to discuss prognosis with patients. Our culture places the highest value on knowledge that allows us to control our environment - thus, the lack of control

Uncertainty in Prognosis to Patients with ESRD that uncertainty carries with it renders it unacceptable [7], especially in a field like medicine, which is founded on the pursuit of unequivocal proof. This binary of 'uncertainty' vs. 'control' causes providers anxiety when they are faced with any of the former. In a renal care setting, providers face challenges of both probabilistic and ethical uncertainties [41, 42] when assessing prognostic outcomes. However, this does not mean that a nephrologist must feel anxious whenever discussing prognosis, which is by its very nature rife with uncertainty $[43,44]$. Medicine is a science, but it is also an art that relies on the provider's personal knowledge of her/his patients when managing them $[45,46]$. It is an art because it allows room for individual subjectivities and values during the application of objective medical science [46]. Providers should eliminate unnecessary uncertainty through continuous self-education $[7,47]$, but the uncertainty of predictions is part of the challenge and complexity of medicine. Physicians diagnosed with chronic illnesses often transform their perspectives on communicating with their patients [30]. Reading such narratives can help us reflect on the uncertainty already present in our patient encounters and help us become more comfortable with a conscious expression of uncertainty to our patients (table 1).

To communicate prognostic uncertainty effectively, it is necessary for providers to be trained for communication skills. While guidelines, such as the RPA/ASN's Shared Decision-Making in the Appropriate Initiation and Withdrawal of Dialysis exist to encourage physicians to conduct prognostic discussions with patients, instructions on how to carry out these guidelines are less clear. One strategy that has been highly recommended is communication skills training. For example, after nephrology fellows participated in a 4-hour communication skills workshop that taught them how to deliver bad news, express empathy, and define goals of care; most of them agreed that they felt more comfortable discussing related issues and that the curriculum should be made compulsory for all nephrology fellows [48]. Notably, only onethird of them had previously been trained in discussing dialysis initiation and withdrawal with patients [48].

Taking time to understand our patients' preferences can help improve communication. We must make sure that uncertainty in discussing prognosis is owing to deficiencies in available data and not owing to our method of communicating it. In general, patients' and physicians' interpretation of statistical information often differs enough that both parties leave the consultation with completely different understandings of what transpired [7,35, $44,49-51]$. Reliance on statistics is even more tenuous in 
Table 1. List of selected resources for implementing approaches to conveying prognostic uncertainty to patients

\section{Confronting uncertainty}

Recommended reading for conceptualizing the lived experience of medical uncertainty: Interacting with Their Patients in Klitzman, Robert. When doctors become patients. New York: Oxford University Press, 2008

Recommended reading for understanding the uncertainty of predictive instruments: Gigerenzer, Gerd. Risk Savvy: How to Make Good Decisions. Penguin Group Press, 2014

Communicating uncertainty

Renal Physicians Association - Shared Decision-Making in the appropriate Initiation and Withdrawal from Dialysis: Clinical Practice Guideline. Available online at http://www.renalmd.org/WorkArea/DownloadAsset.aspx?id=2710

American Society of Nephrology - Improving dialysis rounds. Available online at https://www.asn-online.org/kidneydisease/ geriatrics/rounds/

Nephrotalk: Improving the Nephrologists' Communication Skills. Available online at http://conference-cast.com/ASN/common/ presentations.aspx/6/80/393

Coalition for Supportive Care of Kidney Patients - Advance Care Planning: For Dialysis Patients and Their Families. Available online at http://www.kidneysupportivecare.org/Files/ACPBrochure-E.aspx

Vital Talk - Offer Prognostic Information. Available online at http://vitaltalk.org/clinicians/offer-prognostic-information

Ghosh, AK - Understanding Medical Uncertainty: A Primer for Physicians. Available online at http://japi.org/ september2004/R-739.pdf

NURSE mnemonic for empathic responses during a clinical encounter: Naming, Understanding, Respecting, Supporting, and Exploring

\section{Demonstrating commitment to patient care}

American Nephrology Nurses' Association - End-of-Life Decision-Making and the Role of the Nephrology Nurse. Available online at http://www.annanurse.org

National Kidney Foundation Council of Nephrology Social Workers - CNSW Care Planning Resource Toolkit. Available online at http://www.therenalnetwork.org/home/resources/CfC_sw_CNSWCarePlanningResourceToolkit.pdf

Revisit prognosis longitudinally to reassess alignment between therapeutic modality and patient goals

nephrology, where CKD patients often have poor health numeracy skills [52]. Resources to aid in improving communication with our ESRD patients are listed (table 1) and the future development and validation of decision aids for this purpose would be helpful.

The third step in this approach is to utilize an interdisciplinary team to provide care for ESRD patients as this demonstrates a commitment to them even in the face of prognostic uncertainty. An interdisciplinary team is crucial in delivering dialysis care because it offers diverse perspectives and can often provide in-depth knowledge of patients and their families that nephrologists themselves may not be able to access. Often, physicians do not have the experience needed to address all of the psychosocial needs of patients, but other members of the interdisciplinary team, such as nurse practitioners [53] and social workers [54] are well-versed at educating patients. In an interdisciplinary care team, communication is increased among team members and the result is greater advocacy on behalf of the patient [55]. The physician role remains central, for while patients with ESRD trust all members of their healthcare team, they prefer that the discussion of their prognosis is initiated by their physician [39]. Ultimately, patients most desire meaningful communication with their physicians $[2,44]$. The presence of uncertainty can sometimes impede further communication between the physician and the patient, so addressing it explicitly [7] and expressing humility [44] on the physician's part can facilitate an open discussion and provide a patient comfort amid an often-tumultuous physical and emotional illness experience [56]. As one patient put it, 'I understand you can't make up an answer where there is none... but it's the way you say it that counts. I think you'd find that a lot of patients can deal with uncertainty, provided it's explained properly' [44]. This can be done when members of an interdisciplinary team are mindful of how to communicate uncertainty while maintaining empathy and commitment (table 1). 
Education provision and frequent contact with a team of providers enable patients to make decisions about their care $[55,57]$ and face prognostic uncertainty in a better manner.

\section{Conclusion}

Once we learn how to embrace uncertainty and incorporate it into our discussions of prognosis, the benefits are substantial. By avoiding vagueness [15] and by clearly communicating the presence of prognostic uncertainty to our patients and their surrogates, patients may develop increased trust in their physicians [13]. Uncertainty allows patients the space to hope for the best and prepare for the worst $[13,14]$. Although initially disclosure of uncertainty can decrease patient satisfaction, over time it establishes realistic expectations between the patient and the physician [7], leading to partnership built on honesty and collaboration. As physicians learn to tactfully express uncertainty, it improves their therapeutic effectiveness [58].

Dialysis patients are significantly more optimistic about their prognostic outcomes than their nephrologists, which in turn influence their decisions for future care [25]. Once physicians accept the uncertainty inherent in prognosis, and in turn normalize it for their patients as well, the result can be a collaboration that welcomes the messy complexities of individual experiences of ESRD instead of fostering the anxiety that comes from denying them.

\section{References}

1 Oxford English Dictionary: 'Prognosis, n.': Oxford University Press.

2 Holloway RG, Gramling R, Kelly AG: Estimating and communicating prognosis in advanced neurologic disease. Neurology 2013; 80:764-772.

-3 Yourman LC, Lee SJ, Schonberg MA, Widera EW, Smith AK: Prognostic indices for older adults: a systematic review. JAMA 2012;307: 182-192.

4 Gill TM: The central role of prognosis in clinical decision making. JAMA 2012;307:199-200.

5 Denny K: Evidence-based medicine and medical authority. J Med Humanit 1999;20:247-263.

6 Katz J: The Silent World of Doctor and Patient. Johns Hopkins University Press, 2002.

7 Quill TE, Suchman AL: Uncertainty and control: learning to live with medicine's limitations. Humane Med 1993;9:109-120.

$\checkmark 8$ Christakis NA, Iwashyna TJ: Attitude and self-reported practice regarding prognostication in a national sample of internists. Arch Intern Med 1998;158:2389-2395.

9 Collins AJ, Foley R, Herzog C, Chavers B, Gilbertson D, Ishani A, et al: Excerpts from the United States Renal Data System 2007 annual data report. Am J Kidney Dis 2008;51 (1 suppl 1):S1-S320.

10 Christakis NA: Death Foretold: Prophecy and Prognosis in Medical Care. University of Chicago Press, 2001.

11 Davison SN: End-of-life care preferences and needs: perceptions of patients with chronic kidney disease. Clin J Am Soc Nephrol 2010; 5:195-204.

12 Fine A, Fontaine B, Kraushar MM, Rich BR: Nephrologists should voluntarily divulge survival data to potential dialysis patients: a questionnaire study. Perit Dial Int 2005;25:269-273.

13 Evans LR, Boyd EA, Malvar G, Apatira L, Luce JM, Lo B, et al: Surrogate decision-mak- ers' perspectives on discussing prognosis in the face of uncertainty. Am J Respir Crit Care Med 2009;179:48-53.

14 Hagerty RG, Butow PN, Ellis PM, Lobb EA, Pendlebury SC, Leighl N, et al: Communicating with realism and hope: incurable cancer patients' views on the disclosure of prognosis. J Clin Oncol 2005;23:1278-1288.

15 Kirk P, Kirk I, Kristjanson LJ: What do patients receiving palliative care for cancer and their families want to be told? A Canadian and Australian qualitative study. BMJ 2004;328: 1343.

16 Foucault M: The Birth of the Clinic: An Archaeology of Medical Perception. Routledge, 1973.

17 Timmermans S, Angell A: Evidence-based medicine, clinical uncertainty, and learning to doctor. J Health Soc Behav 2001;42:342-359.

18 Eddy DM: Variations in physician practice: the role of uncertainty. Health Aff (Millwood) 1984;3:74-89.

19 Rockhill B: Theorizing about causes at the individual level while estimating effects at the population level: implications for prevention. Epidemiology 2005;16:124-129.

20 Fox RC: Training for uncertainty; in Merton RK, Reader G, Kendall PL (eds): The student physician. Harvard University Press, 1957, pp 207-241.

21 Blanch DC, Hall JA, Roter DL, Frankel RM: Is it good to express uncertainty to a patient? Correlates and consequences for medical students in a standardized patient visit. Patient Educ Couns 2009;76:300-306.

22 A controlled trial to improve care for seriously ill hospitalized patients. The study to understand prognoses and preferences for outcomes and risks of treatments (SUPPORT) The SUPPORT Principal Investigators. JAMA 1995;274:1591-1598.
23 Lynn J, De Vries KO, Arkes HR, Stevens M, Cohn F, Murphy P, et al: Ineffectiveness of the SUPPORT intervention: review of explanations. J Am Geriatr Soc 2000;48(5 suppl): S206-S213.

24 Lamont EB, Christakis NA: Prognostic disclosure to patients with cancer near the end of life. Ann Intern Med 2001;134:1096-1105.

25 Wachterman MW, Marcantonio ER, Davis RB, Cohen RA, Waikar SS, Phillips RS, et al: Relationship between the prognostic expectations of seriously ill patients undergoing hemodialysis and their nephrologists. JAMA Intern Med 2013;173:1206-1214.

26 Song MK, Lin FC, Gilet CA, Arnold RM, Bridgman JC, Ward SE: Patient perspectives on informed decision-making surrounding dialysis initiation. Nephrol Dial Transplant 2013;28:2815-2823.

27 Song MK, Ward SE: The extent of informed decision-making about starting dialysis: does patients' age matter? J Nephrol 2014;27:571576.

28 Michel DM, Moss AH: Communicating prognosis in the dialysis consent process: a patientcentered, guideline-supported approach. Adv Chronic Kidney Dis 2005;12:196-201.

29 Schell JO, Patel UD, Steinhauser KE, Ammarell N, Tulsky JA: Discussions of the kidney disease trajectory by elderly patients and nephrologists: a qualitative study. Am J Kidney Dis 2012;59:495-503.

30 Klitzman R, Connelly JE: When Doctors Become Patients. Oxford University Press, New York, 2008.

31 Madar H, Bar-Tal Y: The experience of uncertainty among patients having peritoneal dialysis. J Adv Nurs 2009;65:1664-1669.

32 Gordon GH, Joos SK, Byrne J: Physician expressions of uncertainty during patient encounters. Patient Educ Couns 2000;40:59-65. 
-33 Johnson CG, Levenkron JC, Suchman AL, Manchester R: Does physician uncertainty affect patient satisfaction? J Gen Intern Med 1988;3:144-149.

$>34$ Parascandola M, Hawkins J, Danis M: Patient autonomy and the challenge of clinical uncertainty. Kennedy Inst Ethics J 2002;12:245264.

>35 Politi MC, Clark MA, Ombao H, Legare F: The impact of physicians' reactions to uncertainty on patients' decision satisfaction. J Eval Clin Pract 2011;17:575-578.

>36 Ogden J, Fuks K, Gardner M, Johnson S, McLean M, Martin P, et al: Doctors expressions of uncertainty and patient confidence. Patient Educ Couns 2002;48:171-176.

$>37$ Ahalt C, Walter LC, Yourman L, Eng C, Perez-Stable EJ, Smith AK: 'Knowing is better' preferences of diverse older adults for discussing prognosis. J Gen Intern Med 2012;27: 568-575.

-38 Back AL, Arnold RM: Discussing prognosis: 'how much do you want to know?' Talking to patients who are prepared for explicit information. J Clin Oncol 2006;24:4209-4213.

-39 Davison SN: Facilitating advance care planning for patients with end-stage renal disease: the patient perspective. Clin J Am Soc Nephrol 2006; 1:1023-1028.

40 Davison SN, Simpson C: Hope and advance care planning in patients with end stage renal disease: qualitative interview study. BMJ 2006;333:886
41 Grönlund CE, Dahlqvist V, Söderberg AI: Feeling trapped and being torn: physicians' narratives about ethical dilemmas in hemodialysis care that evoke a troubled conscience. BMC Med Ethics 2011;12:8.

42 Jones C: Stress and coping strategies in renal staff. Nurs Times 2014;110:22-25.

43 Smith AK, White DB, Arnold RM: Uncertainty - the other side of prognosis. N Engl J Med 2013;368:2448-2450.

44 Srivastava R: Dealing with uncertainty in a time of plenty. N Engl J Med 2011;365:22522253.

45 Wellbery C: The value of medical uncertainty? Lancet 2010;375:1686-1687.

46 Saunders J: The practice of clinical medicine as an art and as science. Med Humanit 2000; 26:18-22.

47 Gigerenzer G: Risk Savvy: How to Make Good Decisions. Penguin Group US, 2014.

48 Schell JO, Green JA, Tulsky JA, Arnold RM: Communication skills training for dialysis decision-making and end-of-life care in nephrology. Clin J Am Soc Nephrol 2013;8:675680.

49 Ghosh AK: Understanding medical uncertainty: a primer for physicians. J Assoc Physicians India 2004;52:739-742.

50 Reach G: Clinical inertia, uncertainty and in dividualized guidelines. Diabetes Metab 2014 40:241-245.
51 Thorne S, Hislop TG, Kuo M, Armstrong EA: Hope and probability: patient perspectives of the meaning of numerical information in cancer communication. Qual Health Res 2006; 16:318-336.

52 Abdel-Kader K, Dew MA, Bhatnagar M, Argyropoulos C, Karpov I, Switzer G, et al: Numeracy skills in ckd: correlates and outcomes. Clin J Am Soc Nephrol 2010;5:1566-1573.

53 Sciamanna CN, Alvarez K, Miller J, Gary T, Bowen M: Attitudes toward nurse practitioner-led chronic disease management to improve outpatient quality of care. Am J Med Qual 2006;21:375-381.

54 Callahan MB: The role of the nephrology social worker in optimizing treatment outcomes for end-stage renal disease patients. Dialysis Transplant 2011;40:444-450.

55 Saxena N, Rizk D: The interdisciplinary team: the whole is larger than the parts. Adv Chronic Kidney Dis 2014;21:333-337.

56 Dizon DS, Politi MC, Back AL: The power of words: discussing decision making and prognosis. Am Soc Clin Oncol Educ Book 2013; 442-446.

57 Davis JS, Zuber K: The nephrology interdisciplinary team: an education synergism. Adv Chronic Kidney Dis 2014;21:338-343.

58 Tai-Seale M, Stults C, Zhang W, Shumway M: Expressing uncertainty in clinical interactions between physicians and older patients: what matters? Patient Educ Couns 2012;86: 322-328. 